\title{
Transitions of Liver and Biliary Enzymes during Proton Beam Therapy for Hepatocellular Carcinoma
}

\author{
Taisuke Sumiya ${ }^{1,2}$, Masashi Mizumoto ${ }^{1, *(D)}$, Yoshiko Oshiro ${ }^{1,2}$, Keiichiro Baba ${ }^{1}$, \\ Motohiro Murakami ${ }^{1}$, Shosei Shimizu ${ }^{1}$ (D), Masatoshi Nakamura ${ }^{1}$, Yuichi Hiroshima ${ }^{1}$, \\ Toshiki Ishida ${ }^{1}$, Takashi Iizumi ${ }^{1}$, Takashi Saito ${ }^{1}$, Haruko Numajiri ${ }^{1}$, Kei Nakai ${ }^{1}{ }^{\mathbb{D}}$, \\ Toshiyuki Okumura ${ }^{1}$ and Hideyuki Sakurai ${ }^{1}$
}

1 Department of Radiation Oncology, Proton Medical Research Center, University of Tsukuba Hospital, Tsukuba 305-8576, Japan; sumiya.taisuke@gmail.com (T.S.); ooyoshiko@hotmail.com (Y.O.); baba@pmrc.tsukuba.ac.jp (K.B.); murakami@pmrc.tsukuba.ac.jp (M.M.); shimizu@pmrc.tsukuba.ac.jp (S.S.); nakamura@pmrc.tsukuba.ac.jp (M.N.); hiroshima@pmrc.tsukuba.ac.jp (Y.H.); tishida@pmrc.tsukuba.ac.jp (T.I.); iizumi@pmrc.tsukuba.ac.jp (T.I.); saitoh@pmrc.tsukuba.ac.jp (T.S.); haruko@pmrc.tsukuba.ac.jp (H.N.); knakai@pmrc.tsukuba.ac.jp (K.N.); okumura@pmrc.tsukuba.ac.jp (T.O.); hsakurai@pmrc.tsukuba.ac.jp (H.S.)

2 Department of Radiation Oncology, Tsukuba Medical Center Hospital, Tsukuba 305-8558, Japan

* Correspondence: mizumoto@pmrc.tsukuba.ac.jp; Tel.: +81-29-853-7100; Fax: +81-29-853-7102

Received: 1 June 2020; Accepted: 6 July 2020; Published: 8 July 2020

\begin{abstract}
Proton beam therapy (PBT) is a curative treatment for hepatocellular carcinoma (HCC), because it can preserve liver function due to dose targeting via the Bragg peak. However, the degree of direct liver damage by PBT is unclear. In this study, we retrospectively analyzed liver/biliary enzymes and total bilirubin (T-Bil) as markers of direct liver damage during and early after PBT in 300 patients. The levels of these enzymes and bilirubin were almost stable throughout the treatment period. In patients with normal pretreatment levels, aminotransferase (AST), alanine aminotransferase (ALT), alkaline phosphatase (ALP), gamma-glutamyl transpeptidase (GGT), and T-Bil were abnormally elevated in only $2(1.2 \%), 1(0.4 \%), 0,2(1.2 \%)$, and $8(3.5 \%)$ patients, respectively, and in 8 of these 13 patients $(61.5 \%)$ the elevations were temporary. In patients with abnormal pretreatment levels, the levels tended to decrease during PBT. GGT and T-Bil were elevated by 1.62 and 1.57 times in patients who received 66 Gy (RBE) in 10 fractions and 74 Gy (RBE) in 37 fractions, respectively, but again these changes were temporary. These results suggest that direct damage to normal liver caused by PBT is minimal, even if a patient has abnormal pretreatment enzyme levels.
\end{abstract}

Keywords: radiotherapy; proton beam therapy; hepatocellular carcinoma; liver; liver and biliary enzymes; bilirubin

\section{Introduction}

Hepatocellular carcinoma (HCC) is the most common cancer in the liver, accounting for approximately $90 \%$ of primary liver cancers [1-3]. Surgery is the first treatment choice, but highly accurate radiotherapy has also been used in recent years [4-6]. As one modality of radiotherapy, we have obtained many favorable results of proton beam therapy (PBT) for HCC [7-22], including good preservation of liver function after PBT [21]. However, liver function defined by the Child-Pugh score and indocyanine green retention rate at $15 \mathrm{~min}$ (ICG-R15) can be affected by tumor progression or liver cirrhosis, and this can make direct liver damage due to radiotherapy unclear. Therefore, in this 
study, we examined direct liver damage based on analysis of hepatobiliary enzymes and bilirubin, as markers of damage to hepatocytes and cholangiocytes [23-28].

\section{Results}

\subsection{Patients Characteristics}

The patients' characteristics are shown in Table 1. The patients included 219 males and 81 females, and had a median age of 73 (range 27 to 91) years old. The Child classification was A in 237 patients (Pugh scores of 5 in 165 and 6 in 72 patients), B in 62 patients (Pugh scores of 7 in 36, 8 in 19, and 9 in 7 patients), and C in 1 patient (Pugh score of 10). Hepatitis B and C were present in 51 and 140 patients, respectively, and 44 patients had alcoholic liver cirrhosis. Portal vein tumor thrombosis (PVTT) was observed in 48 patients: $\mathrm{Vp} 1$ in $3, \mathrm{Vp} 2$ in $16, \mathrm{Vp} 318$, and $\mathrm{Vp} 4$ in 11. The three PBT protocols of 66 Gy (relative biological effectiveness (RBE)) in 10 fractions (10fr group), $72.6 \mathrm{~Gy}$ (RBE) in 22 fractions (22fr group), and $74 \mathrm{~Gy}$ (RBE) in 37 fractions (37fr group) were administered in 77 (26\%), 148 (50\%), and 75 $(20 \%)$ patients, respectively. All patients received no additional therapy for HCC within 3 months after completion of PBT.

Table 1. Characteristics of patients and tumors.

\begin{tabular}{|c|c|c|c|c|}
\hline Proton Therapy & Total & $\begin{array}{l}66 \text { Gy (RBE)/ } \\
10 \text { Fractions }\end{array}$ & $\begin{array}{l}72.6 \text { Gy }(\mathrm{RBE}) / \\
22 \text { Fractions }\end{array}$ & $\begin{array}{l}74 \text { Gy }(\mathrm{RBE}) / \\
37 \text { Fractions }\end{array}$ \\
\hline Patient number (\%) & 300 & $77(25.7 \%)$ & $148(49.3 \%)$ & $75(25 \%)$ \\
\hline Median age (range) & $73(27-91)$ & $70(42-88)$ & $72.5(33-91)$ & 77 (27-91) \\
\hline \multicolumn{5}{|l|}{ Gender } \\
\hline Male & $219(73 \%)$ & $53(68.8 \%)$ & $114(77 \%)$ & $52(69.3 \%)$ \\
\hline Female & $81(27 \%)$ & $24(31.2 \%)$ & $34(23 \%)$ & $23(30.7 \%)$ \\
\hline \multicolumn{5}{|l|}{ Alcoholic } \\
\hline \multicolumn{5}{|l|}{ liver cirrhosis } \\
\hline No & $256(85.3 \%)$ & $69(89.6 \%$ & $121(81.8 \%)$ & $66(88 \%)$ \\
\hline Yes & $44(14.7 \%)$ & $8(10.4 \%)$ & $27(18.2 \%)$ & $9(12 \%)$ \\
\hline \multicolumn{5}{|l|}{ Hepatitis B } \\
\hline No & $249(83 \%)$ & $65(84.4 \%)$ & $120(81.1 \%)$ & $64(85.3 \%)$ \\
\hline Yes & $51(17 \%)$ & $12(15.6 \%)$ & $28(18.9 \%)$ & $11(14.7 \%)$ \\
\hline \multicolumn{5}{|l|}{ Hepatitis C } \\
\hline No & $160(53.3 \%)$ & $35(45.5 \%)$ & $86(58.1 \%)$ & $39(52 \%)$ \\
\hline Yes & $140(46.7 \%)$ & $42(54.5 \%)$ & $62(41.9 \%)$ & $36(48 \%)$ \\
\hline \multicolumn{5}{|l|}{ Pugh score } \\
\hline 5 & $165(55 \%)$ & $48(62.3 \%)$ & $79(53.4 \%)$ & $38(50.7 \%)$ \\
\hline 6 & $72(24 \%)$ & $16(20.8 \%)$ & $35(23.6 \%)$ & $21(28 \%)$ \\
\hline 7 & $36(12 \%)$ & $7(9.1 \%)$ & $17(11.5 \%)$ & $12(16 \%)$ \\
\hline 8 & $19(6.3 \%$ & $5(6.5 \%)$ & $12(8.1 \%)$ & $2(2.7 \%)$ \\
\hline 9 & $7(2.3 \%)$ & $1(1.3 \%)$ & $4(2.7 \%)$ & $2(2.7 \%)$ \\
\hline 10 & $1(0.3 \%)$ & $0(0 \%)$ & $1(0.7 \%)$ & $0(0 \%)$ \\
\hline \multicolumn{5}{|c|}{ Portal vein thrombosis $(\mathrm{Vp})$} \\
\hline 0 & $252(84 \%)$ & $77(100 \%)$ & $111(75 \%)$ & $64(85.3 \%)$ \\
\hline 1 & $3(1 \%)$ & $0(0 \%)$ & $3(2 \%)$ & $0(0 \%)$ \\
\hline 2 & $16(5.3 \%)$ & $0(0 \%)$ & $12(8.1 \%)$ & $4(5.3 \%)$ \\
\hline 3 & $18(6 \%)$ & $0(0 \%)$ & $13(8.8 \%)$ & $5(6.7 \%)$ \\
\hline 4 & $11(3.7 \%)$ & $0(0 \%)$ & $9(6.1 \%)$ & $2(2.7 \%)$ \\
\hline Median CTV (cc) & $84.5(3-3236)$ & $23.5(7-337)$ & $93(3-3236)$ & $113(6-1681)$ \\
\hline \multicolumn{5}{|c|}{ Median pretreatment values (range) } \\
\hline AST (U/l) & $36(7-199)$ & $36(7-105)$ & $35.5(13-171)$ & 37 (13-199) \\
\hline ALT (U/l) & $27(4-145)$ & $28(8-94)$ & $26(4-145)$ & $26(6-82)$ \\
\hline $\operatorname{ALP}(\mathrm{U} / \mathrm{l})$ & $294(78-1869)$ & 269 (110-652) & $292.5(78-1162)$ & 308 (129-1869) \\
\hline GGT (U/l) & $55(13-1435)$ & $51(13-431)$ & $59(13-1435)$ & $54(16-599)$ \\
\hline T-Bil (mg/dl) & $0.8(0.2-4.9)$ & $0.9(0.2-3.7)$ & $0.9(0.2-4.9)$ & $0.8(0.2-3.1)$ \\
\hline
\end{tabular}


The only differences in patient characteristics and pretreatment laboratory data among the three PBT protocols were for PVTT, biliary enzymes (alkaline phosphatase (ALP) and gamma-glutamyl transpeptidase (GGT)), and clinical target volume (CTV) in the 10fr group. There were no PVTT cases in this group ( $0 \%$ vs. $25 \%$ and $14.7 \%$ in the $22 \mathrm{fr}$ and $37 \mathrm{fr}$ groups, respectively, $p=0.000$ ). Biliary enzymes were lower in the 10fr group than in the other groups, which may have been due to the tumor location and absence of PVTT. CTV was significantly smaller in the 10fr group (23.5 vs. 93 and $113 \mathrm{cc}$ in the 22fr and 37fr groups, respectively, $p<0.001$ ).

\subsection{Transitions of the Laboratory Data}

The levels of enzymes and total bilirubin (T-Bil) were almost stable throughout the treatment period, based on Welch analysis. Changes of these enzymes are shown in Figures 1-3 for the three treatment protocols. Some enzymes decreased after PBT. In the 22fr group, alanine aminotransferase (ALT) was significantly lower at 5 weeks and 2 months compared to the pretreatment level (27.0 and 26.1 vs. $32.1 \mathrm{U} / \mathrm{l}, p=0.0477, p=0.0145$, respectively), and GGT was significantly lower at 3 months after PBT (61.2 vs. 100.0 U/l, $p=0.0107)$. In the 10fr group, T-Bil was significantly lower at 1 month after PBT compared to pretreatment ( 0.7 vs. $1.0 \mathrm{mg} / \mathrm{dl}, p=0.0173$ ).
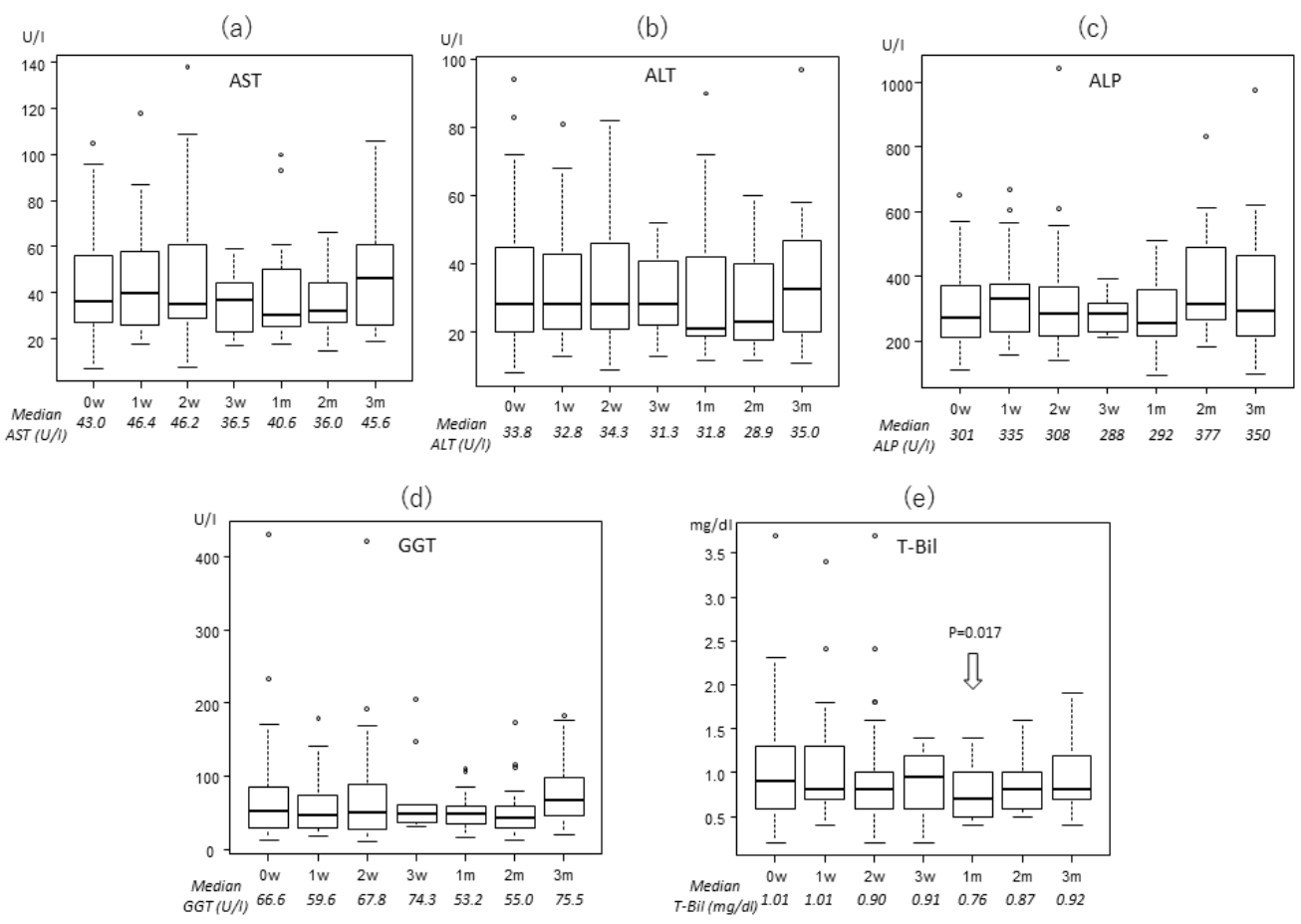

Figure 1. Changes in laboratory data for patients who received 66 Gy (RBE) in 10 fractions: (a) aminotransferase (AST), (b) aminotransferase (ALT), (c) alkaline phosphatase (ALP), (d) gamma-glutamyl transpeptidase (GGT), and (e) total bilirubin (T-Bil). 

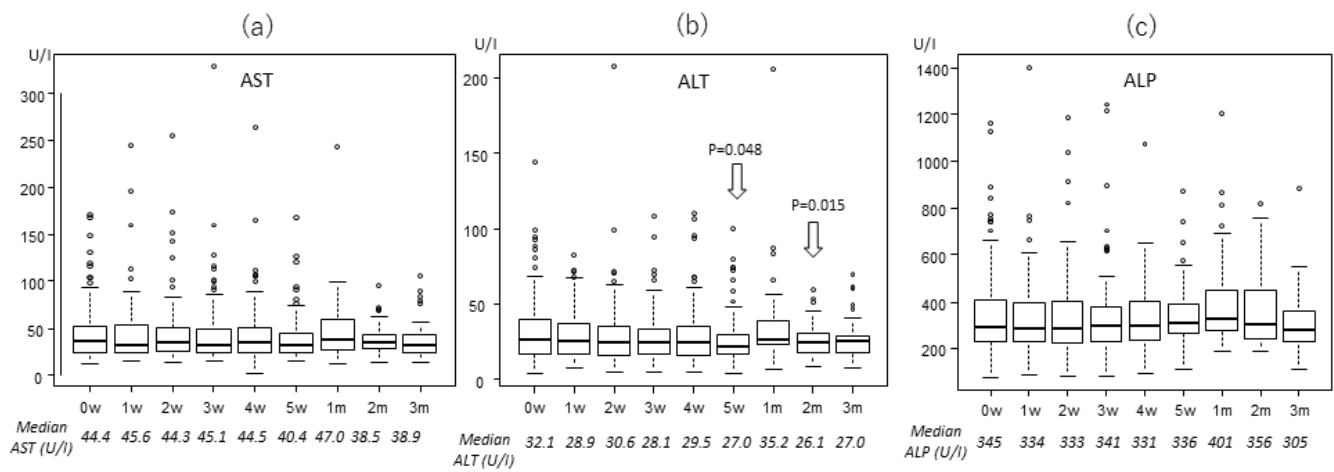

(d)
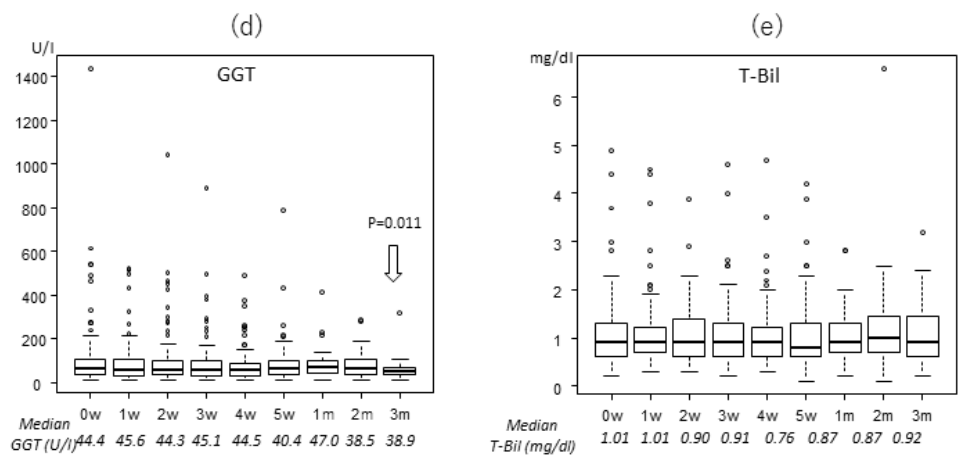

Figure 2. Changes in laboratory data for patients who received $72.6 \mathrm{~Gy}$ (RBE) in 22 fractions: (a) AST, (b) ALT, (c) ALP, (d) GGT, and (e) T-Bil.
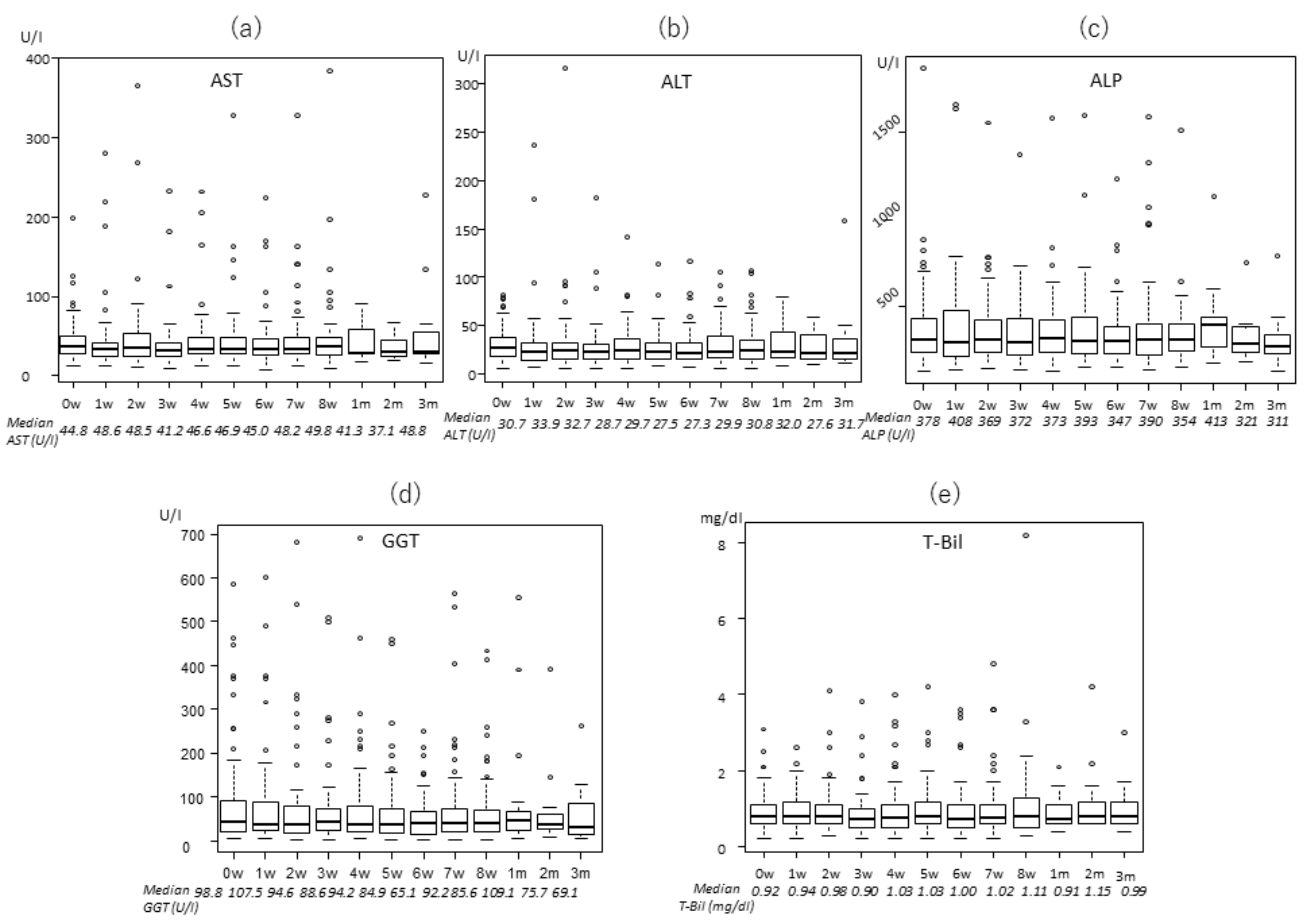

Figure 3. Changes in laboratory data for patients who received $74 \mathrm{~Gy}$ (RBE) in 37 fractions: (a) AST, (b) ALT, (c) ALP, (d) GGT, and (e) T-Bil.

Pretreatment aspartate aminotransferase (AST), ALT, ALP, GGT, and T-Bil had normal values in $163,233,196,171$, and 227 patients, respectively. In these patients, values were abnormally elevated (>Common Terminology Criteria for Adverse Events (CTCAE) grade2) during the treatment period in $2,1,0,2$, and 8 patients, respectively (Table 2). Among these 13 patients, temporary elevation of ALT and GGT occurred in 8 patients, and all these changes recovered. AST elevation occurred in 2 
patients in the 37fr group, and declined in one of these patients. However, AST remained elevated in one patient, and tumor progression out of the treatment field was observed in this case. Elevation of T-Bil was observed in 8 patients in the 22fr group and persisted for over 3 months in 3 patients, for unclear reasons. The significant risk factors for elevation were pretreatment liver function for T-Bil $(p<0.001)$, and CTV for ALP $(p=0.0243)$.

Table 2. Maximum grade of enzymes for patients with normal pretreatment values.

\begin{tabular}{|c|c|c|c|c|c|c|}
\hline \multirow{2}{*}{$\begin{array}{l}\text { Laboratory } \\
\text { Data }\end{array}$} & \multirow{2}{*}{$\begin{array}{l}\text { CTCAE } \\
\text { Grade }\end{array}$} & \multicolumn{3}{|c|}{ Fractionation of PBT } & \multirow{2}{*}{$p$-Value } & \multirow{2}{*}{$\begin{array}{l}\text { Number } \\
\text { of Patients }\end{array}$} \\
\hline & & $10 \mathrm{fr}$ & $22 \mathrm{fr}$ & $37 \mathrm{fr}$ & & \\
\hline \multirow{5}{*}{ AST } & 0 & $32(80 \%)$ & $\begin{array}{c}68 \\
(81.9 \%)\end{array}$ & $\begin{array}{c}27 \\
(67.5 \%)\end{array}$ & \multirow{4}{*}{0.204} & $\begin{array}{c}127 \\
(77.9 \%)\end{array}$ \\
\hline & 1 & $8(20 \%)$ & $\begin{array}{c}15 \\
(18.1 \%)\end{array}$ & $\begin{array}{c}11 \\
(27.5 \%)\end{array}$ & & $\begin{array}{c}34 \\
(20.9 \%)\end{array}$ \\
\hline & 2 & $0(0 \%)$ & $0(0 \%)$ & $1(2.5 \%)$ & & $1(0.6 \%)$ \\
\hline & 3 & $0(0 \%)$ & $0(0 \%)$ & $1(2.5 \%)$ & & $1(0.6 \%)$ \\
\hline & Total & 40 & 83 & 40 & & 163 \\
\hline \multirow{4}{*}{ ALT } & 0 & $\begin{array}{c}51 \\
(89.5 \%)\end{array}$ & $\begin{array}{c}102 \\
(87.9 \%)\end{array}$ & $\begin{array}{c}49 \\
(81.7 \%)\end{array}$ & \multirow{3}{*}{0.429} & $\begin{array}{c}202 \\
(86.7 \%)\end{array}$ \\
\hline & 1 & $6(10.5 \%)$ & $\begin{array}{c}14 \\
(12.1 \%)\end{array}$ & $\begin{array}{c}10 \\
(16.7 \%)\end{array}$ & & $\begin{array}{c}30 \\
(12.9 \%)\end{array}$ \\
\hline & 2 & $0(0 \%)$ & $0(0 \%)$ & $1(1.7 \%)$ & & $1(0.4 \%)$ \\
\hline & Total & 57 & 116 & 60 & & 233 \\
\hline \multirow{3}{*}{ ALP } & 0 & $\begin{array}{c}42 \\
(76.4 \%)\end{array}$ & $\begin{array}{c}73 \\
(76.8 \%)\end{array}$ & $\begin{array}{c}32 \\
(69.6 \%)\end{array}$ & \multirow[t]{2}{*}{0.636} & $\begin{array}{c}147 \\
(75 \%)\end{array}$ \\
\hline & 1 & $\begin{array}{c}13 \\
(23.6 \%) \\
\end{array}$ & $\begin{array}{c}22 \\
(23.2 \%)\end{array}$ & $\begin{array}{c}14 \\
(30.4 \%)\end{array}$ & & $49(25 \%)$ \\
\hline & Total & 55 & 95 & 46 & & 196 \\
\hline \multirow{5}{*}{ GGT } & 0 & $\begin{array}{c}44 \\
(91.7 \%)\end{array}$ & $\begin{array}{c}65 \\
(79.3 \%)\end{array}$ & $\begin{array}{c}36 \\
(87.8 \%)\end{array}$ & \multirow{4}{*}{0.130} & $\begin{array}{c}145 \\
(84.8 \%)\end{array}$ \\
\hline & 1 & $3(6.2 \%)$ & $\begin{array}{c}16 \\
(19.5 \%)\end{array}$ & $5(12.2 \%)$ & & $24(14 \%)$ \\
\hline & 2 & $1(2.1 \%)$ & $0(0 \%)$ & $0(0 \%)$ & & $1(0.6 \%)$ \\
\hline & 3 & $0(0 \%)$ & $1(1.2 \%)$ & $0(0 \%)$ & & $1(0.6 \%)$ \\
\hline & Total & 48 & 82 & 41 & & 171 \\
\hline \multirow{5}{*}{ T-Bil } & 0 & $\begin{array}{c}50 \\
(86.2 \%)\end{array}$ & $85(78 \%)$ & $\begin{array}{c}49 \\
(81.7 \%)\end{array}$ & \multirow{4}{*}{0.105} & $\begin{array}{c}184 \\
(81.1 \%)\end{array}$ \\
\hline & 1 & $8(13.8 \%)$ & $\begin{array}{c}17 \\
(15.6 \%)\end{array}$ & $\begin{array}{c}10 \\
(16.7 \%)\end{array}$ & & $\begin{array}{c}35 \\
(15.4 \%)\end{array}$ \\
\hline & 2 & $0(0 \%)$ & $7(6.4 \%)$ & $0(0 \%)$ & & $7(3.1 \%)$ \\
\hline & 3 & $0(0 \%)$ & $0(0 \%)$ & $1(1.7 \%)$ & & $1(0.4 \%)$ \\
\hline & Total & 58 & 109 & 60 & & 227 \\
\hline
\end{tabular}

Abnormal pretreatment values of AST, ALT, ALP, GGT, and T-Bil were present in 137, 67, 104, 129, and 73 patients, respectively. The range of abnormal values was wide, so changes were evaluated as percentages. The median value was within $-35.9 \%$ to $+62.1 \%$ for all enzymes, and most medians were within $-30 \%$ to $+10 \%$ (Figure 4 ). In patients in the $10 \mathrm{fr}$ group, GGT at 3 weeks was elevated to $+62.1 \%$ but rapidly decreased to $-26.2 \%$ at 1 month after PBT (7 weeks from the start of PBT), and T-Bil was elevated to $+57.3 \%$ at 2 months after PBT but decreased to $+13.3 \%$ at 3 months after PBT. 


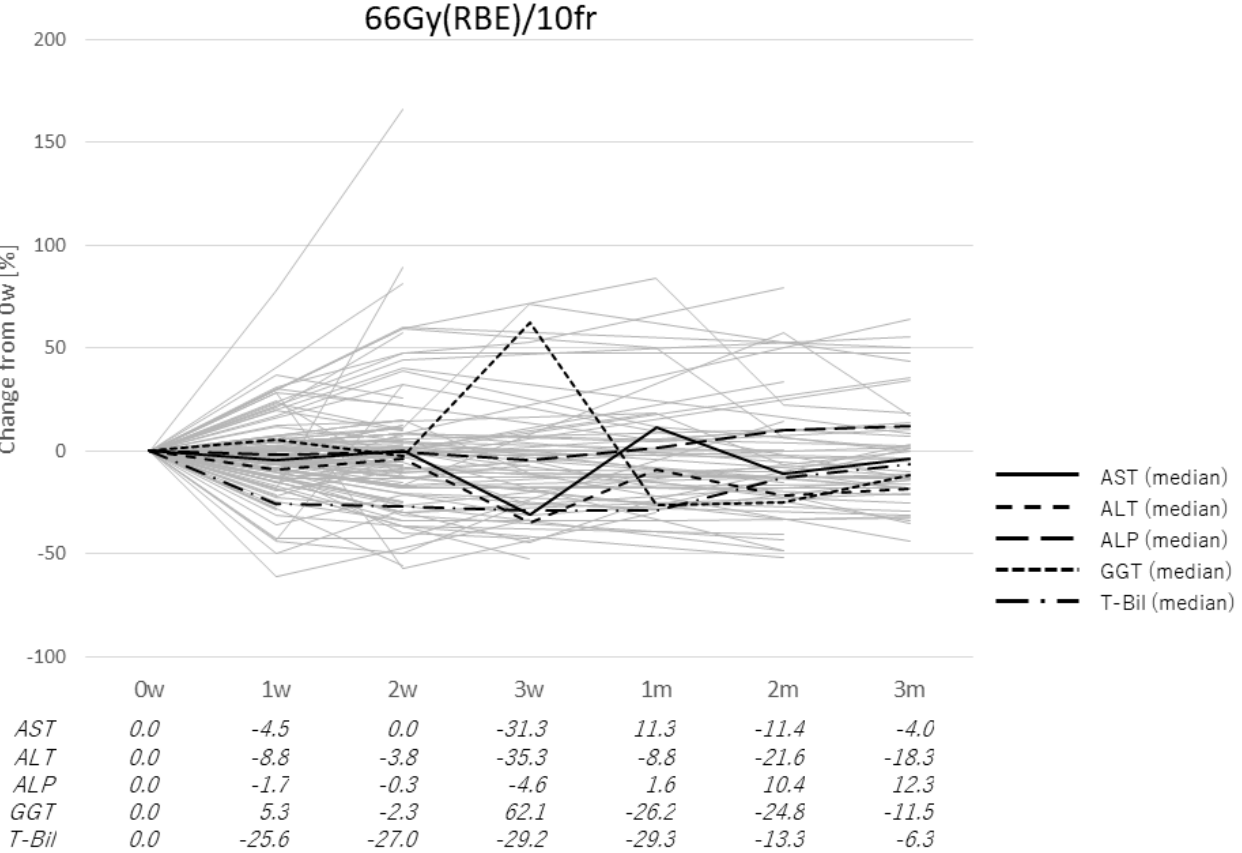

(A)

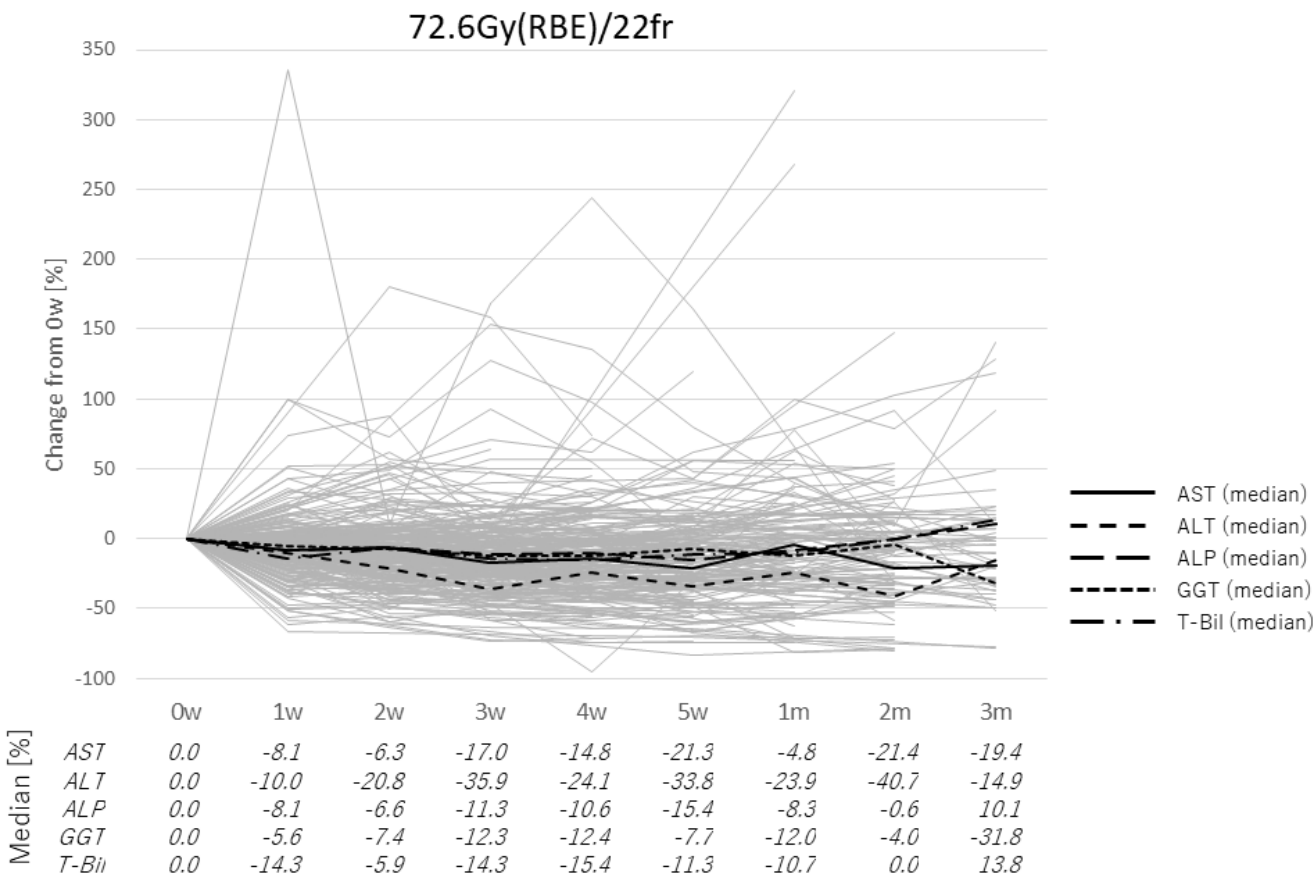

(B)

Figure 4. Cont. 


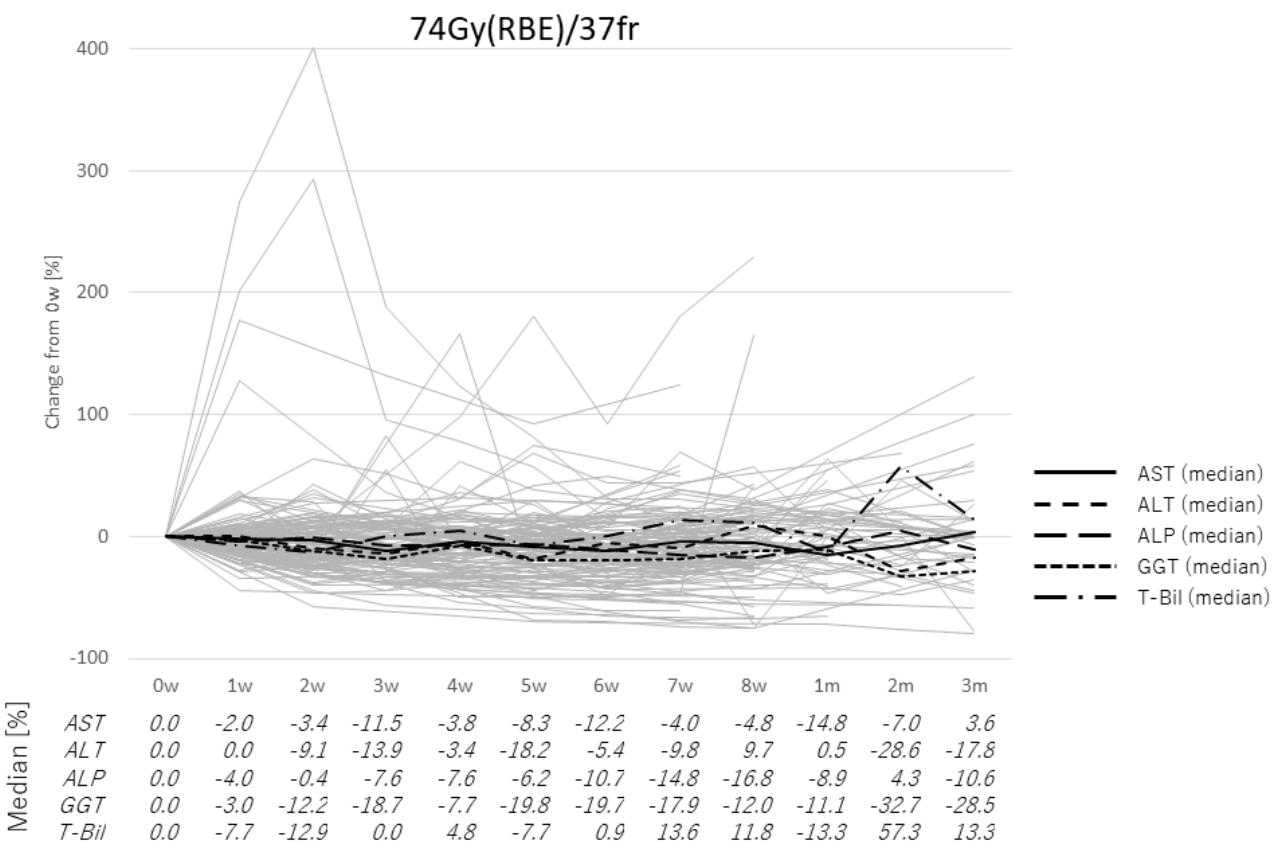

(C)

Figure 4. (A) Changes in laboratory data for patients with abnormal pretreatment values treated by 66Gy (RBE) in 10 fractions. (B) Changes in laboratory data for patients with abnormal pretreatment values treated by $72.6 \mathrm{~Gy}$ (RBE) in 22 fractions. (C) Changes in laboratory data for patients with abnormal pretreatment values treated by 74Gy (RBE) in 37 fractions.

Pretreatment and post treatment Child-Pugh score and ALBI score were also investigated. The median Child-Pugh scores were 5 (range: 5 to 10) at pretreatment period and 6 (range: 5 to 10) at the end of the treatment. The median ALBI scores were -2.43 (range: -3.50 to -0.73 ) at pretreatment period and -2.42 (range: -3.36 to 0.04 ) at the end of the treatment, respectively. There were no significant changes between pre- and post-treatment $(p=0.511$ and $p=0.199$, respectively).

\subsection{Case Presentation}

As a typical example, we present the case of a 64-year-old male patient who received PBT at $72.6 \mathrm{~Gy}$ (RBE) in 22 fractions. The maximum tumor size was $18 \mathrm{~cm}$ in diameter, and the CTV was 3236 cc. Figure 5 shows the treatment planning. The tumor was large and the patch technique [10] was used for this patient, but spreading of the low dose area was minimized. Changes in laboratory data for the patient are shown in Figure 6. The normal pretreatment T-Bil of $1.2 \mathrm{mg} / \mathrm{dl}$ elevated to 2.1 $\mathrm{mg} / \mathrm{dl}$ at 1 week after the start of PBT, and ursodeoxycholic acid was prescribed. T-Bil then declined to $1.2 \mathrm{mg} / \mathrm{dl}$ at 2 months after PBT. The patient survived for 2 years after PBT, but then died due to out-of-field recurrence. 


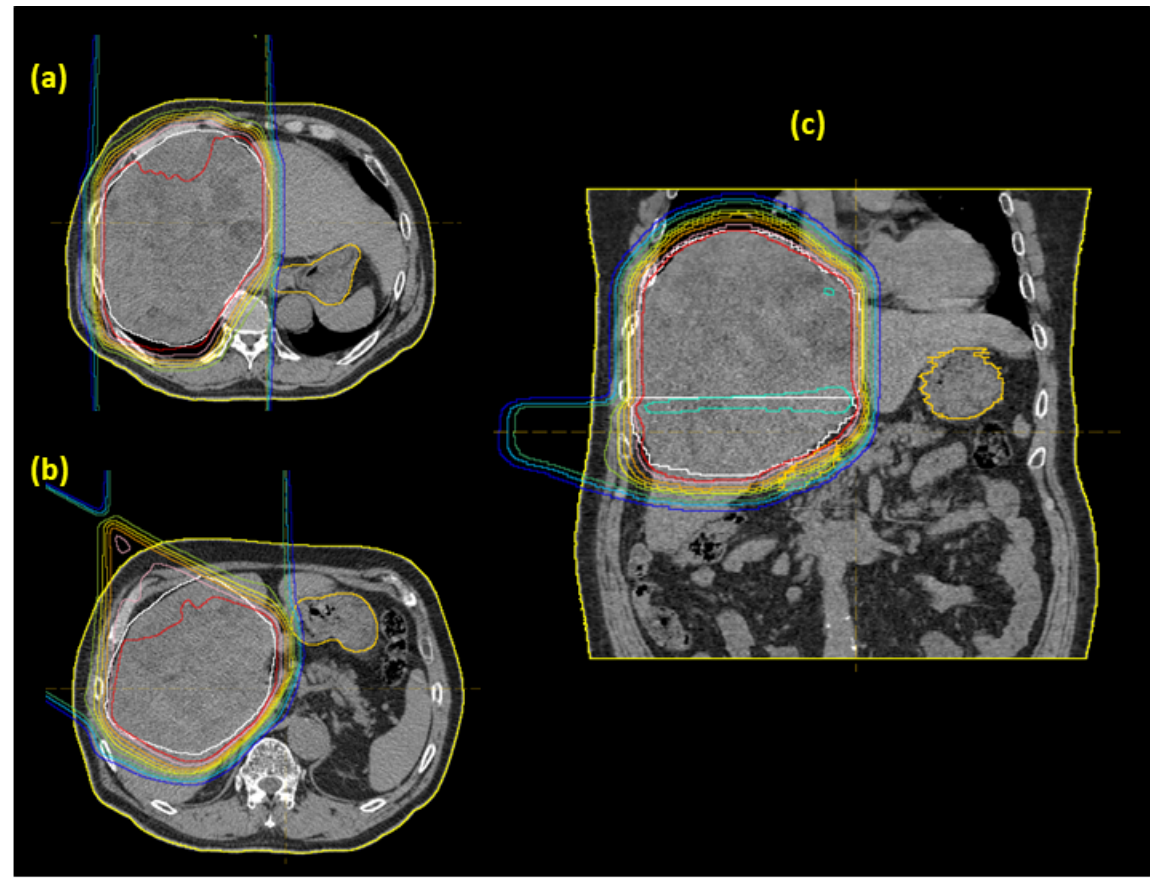

Figure 5. Dose distribution in a 64-year-old patient with a large tumor that was treated using the patch technique: (a) upper treatment field, (b) lower treatment field, and (c) coronal view of the merged fields.

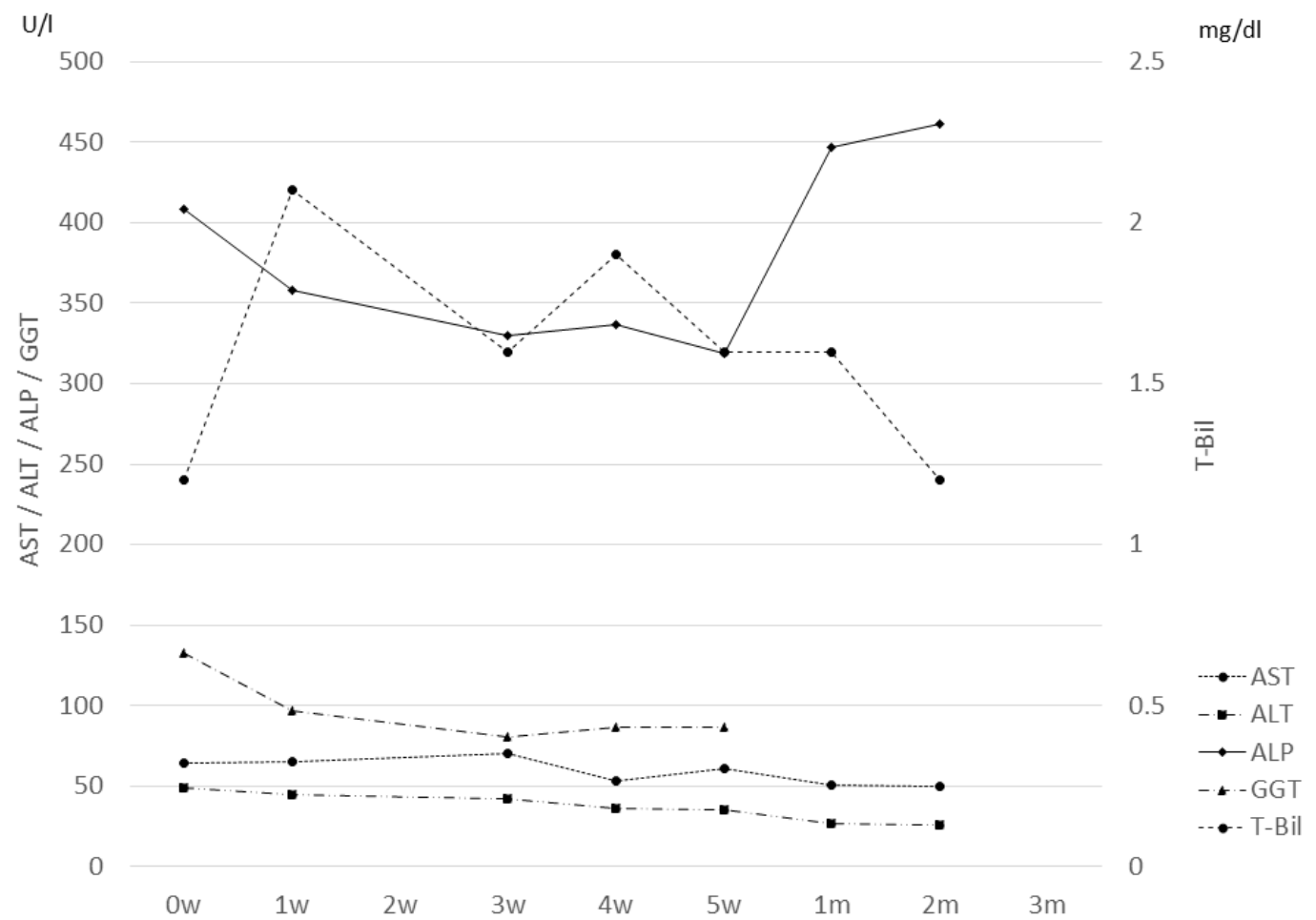

Figure 6. Changes in laboratory data for a 64-year-old patient with a large tumor.

\section{Discussion}

Radiotherapy techniques have progressed in recent decades, and radiotherapy has been used for radical treatment of HCC for patients who are not indicated for surgical resection or ablative therapy. The proton beam used in PBT has a narrow energy peak called the Bragg peak that can reduce the dose area compared to photon beam therapy, such as stereotactic body radiotherapy and intensity 
modulated radiotherapy [29-32]. Therefore, the dose distribution in PBT is favorable for HCC, and PBT is widely indicated for HCC, including in patients with large HCC [10,15] and PVTT [9,14]. The results of PBT for HCC have been favorable, with liver function defined by Child-Pugh score or ICG-R15 well preserved in these reports [20,21]. However, these measures of liver functions are affected by tumor progression or liver cirrhosis. Therefore, to obtain a direct measure of liver damage by PBT, we examined levels of liver/biliary enzymes and T-Bil in the current study.

AST, ALT, and ALP levels are commonly used to evaluate radiation-induced liver disease (RILD) [33]. These enzymes are abundant in hepatocytes and are released when hepatocytes are damaged. ALT is more specific for liver due to its almost exclusive presence in hepatocytes and nephrocytes, whereas AST is also found in the heart and muscle [23-25]. ALP is found on the canalicular membrane in hepatocytes, and its blood level reflects biliary duct obstruction (BDO). ALP can be used to detect a micro-obstruction without an increase of bilirubin, but interpretation of a high ALP level can be difficult because ALP is also present in bone, placenta, intestine, and kidney. GGT, another enzyme in the canalicular membrane, is not found in bone, and thus elevations of both ALP and GGT suggest an effect in liver [23,26]. Bilirubin is a metabolite of old erythrocytes that is excreted in bile after conjugation in the liver and reflects hepatocyte dysfunction or BDO [23,27].

There are a few reports of laboratory data, including these enzymes, related to PBT. In a phase II study of PBT in 76 patients with HCC, Bush et al. found no significant changes in posttreatment AST, ALT, ALP, bilirubin, and albumin levels [34]. In repeated PBT for HCC, Oshiro et al. found no significant elevation of AST, ALT, and platelet count between the first and second PBT [22]. These studies suggest that late elevation of these enzymes and late liver toxicities are minor in PBT.

In this study, liver enzyme levels were almost stable throughout the treatment period, and elevations of enzymes were almost always temporary. In fact, liver and biliary enzymes decreased in some patients, especially in those with tumors at the porta hepatis. This may be due to recovery of hepatocytes or cholestasis through improvement of liver damage caused by the tumor. The CTV was not a significant factor associated with a change of liver enzymes. Generally, the lower dose area as a target volume is extended in photon radiotherapy. In an analysis of the functional liver volume detected by single photon emission computed tomography (SPECT), Shirai et al. observed a dysfunctional liver area induced by photon radiotherapy, with an increased risk of RILD in cases in which a high percentage of the functional liver area was destroyed by the treatment [35]. In contrast, PBT can make a smaller irradiated area due to the Bragg peak. This is one of the reasons that the target volume does not affect laboratory data for liver enzymes.

There are some limitations in this study, including the retrospective design and possible selection bias. Additionally, we do not compare PBT with photon beam therapy; therefore, the actual benefits of PBT are unclear. However, we found that liver and biliary enzymes were almost stable during and early after PBT, and some patients with high enzyme or bilirubin levels had decreased levels after PBT. These results suggest that PBT-induced direct damage of normal liver was minimal.

\section{Materials and Methods}

\subsection{Patients}

PBT was conducted for 1063 HCC lesions between August 2007 and October 2019 at our hospital. Of these cases, 300 patients who received protocol treatment and met the following criteria was retrospectively analyzed (Tsukuba Clinical Research \& Development Organization R01-146): (1) no active lesions out of the target volume, (2) no metastases beyond the liver, (3) no other radiotherapy (including the liver before the treatment), (4) all treatments in the same period and using the same protocol if multiple lesions were treated, (5) laboratory data for more than one time point during treatment, and (6) no unexpected interruptions of treatment. Levels of liver/biliary enzymes, including AST, ALT, ALP, GGT, and T-Bil, were evaluated before and up to three months after PBT. 


\subsection{Proton Beam Therapy}

Fiducial markers (iridium seeds of $2 \mathrm{~mm}$ in length and $0.8 \mathrm{~mm}$ in diameter) were implanted adjacent to the tumor prior to treatment planning. After immobilization of the patient, planning CT images were obtained at 2.5-mm intervals during the expiratory phase using a respiratory gating system (Anzai Medial Co., Tokyo, Japan) [36,37]. The CTV was defined as the gross tumor volume (GTV) plus a 5- to 10-mm margin in all directions. In a case with a PVTT, the margin was extended to $\geq 10 \mathrm{~mm}$. The internal target volume (ITV) was defined as the CTV plus an additional 5-mm margin on the caudal axes to compensate for the uncertainty of respiratory movement. Proton beams from 155 to $250 \mathrm{MeV}$ generated through a linear accelerator and synchrotron were spread out and shaped with ridge filters, double scattering sheets, multicolimators, and a custom-made bolus to ensure that the beams conformed to the planning data.

We selected the fractionations by the tumor locations. When the tumors were adjacent to high-risk organs, the fraction doses were reduced to avoid severe chronic adverse effects: $2 \mathrm{~Gy}$ (RBE) per fraction for the tumors near the gastrointestinal tract to prevent gastrointestinal hemorrhage, 3.3Gy (RBE) per fraction for the tumors near the porta hepatis to prevent severe bleeding and biliary tract obstruction, and 6.6Gy (RBE) for the others. Then, treatment schedules were established as 74 Gy (RBE) in 37 fractions for the tumors within $2 \mathrm{~cm}$ of the gastrointestinal tract, $72.6 \mathrm{~Gy}$ (RBE) in 22 fractions for the tumors within $2 \mathrm{~cm}$ of the porta hepatis, and $66 \mathrm{~Gy}$ (RBE) in 10 fractions for all the other tumors in our institution. The gastrointestinal tract was avoided as far as possible after 40 to $50 \mathrm{~Gy}$ (RBE) irradiated. Previous study has suggested that these three fractionations can achieve similar therapeutic effects [13]. These doses were calculated assuming the RBE to be 1.1.

\subsection{Follow-Up Procedures}

During treatment, acute treatment-related toxicities and treatment efficacy were assessed once or twice per week in all patients. After completion of PBT, physical examinations, blood sampling, and CT or MRI were performed at intervals of several months. If it was difficult for patients to visit our hospital due to traveling distance or a poor general condition, follow up was performed at a nearby hospital and the results were sent to our hospital.

\subsection{Statistical Analysis}

Changes of hepatic/biliary enzymes and T-Bil levels were analyzed for patients with each treatment protocol, because the treatment period differed among the protocols. Differences of patient characteristics among protocols were evaluated by Pearson chi-square test or Fisher exact test [38]. A Welch t-test was used to evaluate weekly changes in laboratory data from pretreatment data [39]. Laboratory data were also classified based on CTCAE v.5.0. All analyses were performed using EZR (http://www.jichi.ac.jp/saitama-sct/SaitamaHP.files/statmed.html), which is based on R (R Foundation for Statistical Computing, Vienna, Austria) [40].

\section{Conclusions}

Our result showed that direct damage to normal liver caused by PBT is minimal and temporary. In addition, the levels of liver and biliary enzymes or bilirubin tend to decrease in the patients with abnormal pretreatment levels.

Author Contributions: Conceptualization, T.S. (Taisuke Sumiya) and M.M. (Masashi Mizumoto); methodology, T.S. (Taisuke Sumiya); formal analysis, T.S. (Taisuke Sumiya); investigation, T.S. (Taisuke Sumiya); resources, T.S. (Taisuke Sumiya), K.B., M.M. (Motohiro Murakami), T.S. (Takashi Saito), T.O., M.M. (Masashi Mizumoto), S.S., M.N., Y.H., T.I. (Toshiki Ishida), T.I. (Takashi Iizumi), H.N., K.N. and H.S.; data curation, T.S. (Taisuke Sumiya); writing—original draft preparation, T.S. (Taisuke Sumiya); writing—review and editing, M.M. (Masashi Mizumoto) and Y.O.; visualization, T.S. (Taisuke Sumiya) and Y.O.; supervision, H.S.; project administration, M.M. (Masashi Mizumoto) and Y.O. All authors have read and agreed to the published version of the manuscript.

Funding: This research received no external funding. 
Acknowledgments: This work was supported in part by a Grant-in-Aid from the Ministry of Education, Science, Sports and Culture of Japan (19H03596).

Conflicts of Interest: The authors declare no conflict of interest.

\section{References}

1. Ghouri, Y.A.; Mian, I.; Rowe, J.H. Review of hepatocellular carcinoma: Epidemiology, etiology, and carcinogenesis. J. Carcinog. 2017, 16. [CrossRef]

2. Mittal, S.; El-Serag, H.B. Epidemiology of HCC: Consider the Population. J. Clin. Gastroenterol. 2013, 47, S2-S6. [CrossRef] [PubMed]

3. El-Serag, H.B.; Rudolph, K.L. Hepatocellular Carcinoma: Epidemiology and Molecular Carcinogenesis. Gastroenterology 2007, 132, 2557-2576. [CrossRef]

4. Omata, M.; Cheng, A.-L.; Kokudo, N.; Kudo, M.; Lee, J.M.; Jia, J.; Tateishi, R.; Han, K.-H.; Chawla, Y.K.; Shiina, S.; et al. Asia-Pacific clinical practice guidelines on the management of hepatocellular carcinoma: A 2017 update. Hepatol. Int. 2017, 11, 317-370. [CrossRef] [PubMed]

5. European Association for the Study of the Liver EASL Clinical Practice Guidelines: Management of hepatocellular carcinoma. J. Hepatol. 2018, 69, 182-236. [CrossRef] [PubMed]

6. Marrero, J.A.; Kulik, L.M.; Sirlin, C.B.; Zhu, A.X.; Finn, R.S.; Abecassis, M.M.; Roberts, L.R.; Heimbach, J.K. Diagnosis, Staging, and Management of Hepatocellular Carcinoma: 2018 Practice Guidance by the American Association for the Study of Liver Diseases. Hepatology 2018, 68, 723-750. [CrossRef] [PubMed]

7. Fukuda, K.; Okumura, T.; Abei, M.; Fukumitsu, N.; Ishige, K.; Mizumoto, M.; Hasegawa, N.; Numajiri, H.; Ohnishi, K.; Ishikawa, H.; et al. Long-term outcomes of proton beam therapy in patients with previously untreated hepatocellular carcinoma. Cancer Sci. 2017, 108, 497-503. [CrossRef]

8. Murakami, M.; Fukumitsu, N.; Okumura, T.; Numajiri, H.; Murofushi, K.; Ohnishi, K.; Mizumoto, M.; Ishikawa, H.; Tsuboi, K.; Sakurai, H. Three cases of hepatocellular carcinoma treated 4 times with proton beams. Mol. Clin. Oncol. 2020, 12, 31-35. [CrossRef]

9. Sekino, Y.; Okumura, T.; Fukumitsu, N.; Iizumi, T.; Numajiri, H.; Mizumoto, M.; Nakai, K.; Nonaka, T.; Ishikawa, H.; Sakurai, H. Proton beam therapy for hepatocellular carcinoma associated with inferior vena cava tumor thrombus. J. Cancer Res. Clin. Oncol. 2020, 146, 711-720. [CrossRef]

10. Nakamura, M.; Fukumitsu, N.; Kamizawa, S.; Numajiri, H.; Nemoto Murofushi, K.; Ohnishi, K.; Aihara, T.; Ishikawa, H.; Okumura, T.; Tsuboi, K.; et al. A validated proton beam therapy patch-field protocol for effective treatment of large hepatocellular carcinoma. J. Radiat. Res. 2018, 59, 632-638. [CrossRef]

11. Fukumitsu, N.; Takahashi, S.; Okumura, T.; Ishida, T.; Murofushi, K.N.; Ohnishi, K.; Aihara, T.; Ishikawa, H.; Tsuboi, K.; Sakurai, H. Normal liver tissue change after proton beam therapy. Jpn. J. Radiol. 2018, 36, 559-565. [CrossRef] [PubMed]

12. Mizumoto, M.; Oshiro, Y.; Okumura, T.; Fukumitsu, N.; Numajiri, H.; Ohnishi, K.; Aihara, T.; Ishikawa, H.; Tsuboi, K.; Sakurai, H. Proton Beam Therapy for Hepatocellular Carcinoma: A Review of the University of Tsukuba Experience. Int. J. Part. Ther. 2016, 2, 570-578. [CrossRef]

13. Mizumoto, M.; Okumura, T.; Hashimoto, T.; Fukuda, K.; Oshiro, Y.; Fukumitsu, N.; Abei, M.; Kawaguchi, A.; Hayashi, Y.; Ookawa, A.; et al. Proton Beam Therapy for Hepatocellular Carcinoma: A Comparison of Three Treatment Protocols. Int. J. Radiat. Oncol. 2011, 81, 1039-1045. [CrossRef]

14. Sugahara, S.; Nakayama, H.; Fukuda, K.; Mizumoto, M.; Tokita, M.; Abei, M.; Shoda, J.; Matsuzaki, Y.; Thono, E.; Tsuboi, K.; et al. Proton-Beam Therapy for Hepatocellular Carcinoma Associated with Portal Vein Tumor Thrombosis. Strahlenther. Onkol. 2009, 185, 782. [CrossRef]

15. Sugahara, S.; Oshiro, Y.; Nakayama, H.; Fukuda, K.; Mizumoto, M.; Abei, M.; Shoda, J.; Matsuzaki, Y.; Thono, E.; Tokita, M.; et al. Proton Beam Therapy for Large Hepatocellular Carcinoma. Int. J. Radiat. Oncol. 2010, 76, 460-466. [CrossRef]

16. Fukumitsu, N.; Sugahara, S.; Nakayama, H.; Fukuda, K.; Mizumoto, M.; Abei, M.; Shoda, J.; Thono, E.; Tsuboi, K.; Tokuuye, K. A Prospective Study of Hypofractionated Proton Beam Therapy for Patients With Hepatocellular Carcinoma. Int. J. Radiat. Oncol. 2009, 74, 831-836. [CrossRef]

17. Mizumoto, M.; Tokuuye, K.; Sugahara, S.; Nakayama, H.; Fukumitsu, N.; Ohara, K.; Abei, M.; Shoda, J.; Tohno, E.; Minami, M. Proton Beam Therapy for Hepatocellular Carcinoma Adjacent to the Porta Hepatis. Int. J. Radiat. Oncol. 2008, 71, 462-467. [CrossRef] 
18. Hata, M.; Tokuuye, K.; Sugahara, S.; Tohno, E.; Nakayama, H.; Fukumitsu, N.; Mizumoto, M.; Abei, M.; Shoda, J.; Minami, M.; et al. Proton Beam Therapy for Aged Patients With Hepatocellular Carcinoma. Int. J. Radiat. Oncol. 2007, 69, 805-812. [CrossRef] [PubMed]

19. Hata, M.; Tokuuye, K.; Sugahara, S.; Fukumitsu, N.; Hashimoto, T.; Ohnishi, K.; Nemoto, K.; Ohara, K.; Matsuzaki, Y.; Akine, Y. Proton Beam Therapy for Hepatocellular Carcinoma Patients with Severe Cirrhosis. Strahlenther. Onkol. 2006, 182, 713. [CrossRef]

20. Mizumoto, M.; Oshiro, Y.; Okumura, T.; Fukuda, K.; Fukumitsu, N.; Abei, M.; Ishikawa, H.; Ohnishi, K.; Numajiri, H.; Tsuboi, K.; et al. Association between pretreatment retention rate of indocyanine green $15 \mathrm{~min}$ after administration and life prognosis in patients with HCC treated by proton beam therapy. Radiother. Oncol. 2014, 113, 54-59. [CrossRef]

21. Mizumoto, M.; Okumura, T.; Hashimoto, T.; Fukuda, K.; Oshiro, Y.; Fukumitsu, N.; Abei, M.; Kawaguchi, A.; Hayashi, Y.; Ohkawa, A.; et al. Evaluation of Liver Function After Proton Beam Therapy for Hepatocellular Carcinoma. Int. J. Radiat. Oncol. 2012, 82, e529-e535. [CrossRef]

22. Oshiro, Y.; Mizumoto, M.; Okumura, T.; Fukuda, K.; Fukumitsu, N.; Abei, M.; Ishikawa, H.; Takizawa, D.; Sakurai, H. Analysis of repeated proton beam therapy for patients with hepatocellular carcinoma. Radiother. Oncol. 2017, 123, 240-245. [CrossRef]

23. Kwo, P.Y.; Cohen, S.M.; Lim, J.K. ACG Clinical Guideline: Evaluation of Abnormal Liver Chemistries. Am. J. Gastroenterol. 2017, 112, 18-35. [CrossRef]

24. Dufour, D.R.; Lott, J.A.; Nolte, F.S.; Gretch, D.R.; Koff, R.S.; Seeff, L.B. Diagnosis and Monitoring of Hepatic Injury. I. Performance Characteristics of Laboratory Tests. Clin. Chem. 2000, 46, 2027-2049. [CrossRef]

25. Dufour, D.R.; Lott, J.A.; Nolte, F.S.; Gretch, D.R.; Koff, R.S.; Seeff, L.B. Diagnosis and Monitoring of Hepatic Injury. II. Recommendations for Use of Laboratory Tests in Screening, Diagnosis, and Monitoring. Clin. Chem. 2000, 46, 2050-2068. [CrossRef]

26. Vroon, D.H.; Israili, Z. Alkaline Phosphatase and Gamma Glutamyltransferase. In Clinical Methods: The History, Physical, and Laboratory Examinations; Walker, H.K., Hall, W.D., Hurst, J.W., Eds.; Butterworths: Boston, MA, USA, 1990.

27. Fevery, J.; Blanckaert, N. What can we learn from analysis of serum bilirubin? J. Hepatol. 1986, 2, $113-121$. [CrossRef]

28. Igaki, H.; Mizumoto, M.; Okumura, T.; Hasegawa, K.; Kokudo, N.; Sakurai, H. A systematic review of publications on charged particle therapy for hepatocellular carcinoma. Int. J. Clin. Oncol. 2018, 23, 423-433. [CrossRef]

29. Wang, X.; Krishnan, S.; Zhang, X.; Dong, L.; Briere, T.; Crane, C.H.; Martel, M.; Gillin, M.; Mohan, R.; Beddar, S. Proton Radiotherapy for Liver Tumors: Dosimetric Advantages Over Photon Plans. Med. Dosim. 2008, 33, 259-267. [CrossRef]

30. Gandhi, S.J.; Liang, X.; Ding, X.; Zhu, T.C.; Ben-Josef, E.; Plastaras, J.P.; Metz, J.M.; Both, S.; Apisarnthanarax, S. Clinical decision tool for optimal delivery of liver stereotactic body radiation therapy: Photons versus protons. Pract. Radiat. Oncol. 2015, 5, 209-218. [CrossRef]

31. Andolino, D.L.; Johnson, C.S.; Maluccio, M.; Kwo, P.; Tector, A.J.; Zook, J.; Johnstone, P.A.S.; Cardenes, H.R. Stereotactic Body Radiotherapy for Primary Hepatocellular Carcinoma. Int. J. Radiat. Oncol. 2011, 81, e447-e453. [CrossRef]

32. Culleton, S.; Jiang, H.; Haddad, C.R.; Kim, J.; Brierley, J.; Brade, A.; Ringash, J.; Dawson, L.A. Outcomes following definitive stereotactic body radiotherapy for patients with Child-Pugh B or C hepatocellular carcinoma. Radiother. Oncol. 2014, 111, 412-417. [CrossRef] [PubMed]

33. Lawrence, T.S.; Robertson, J.M.; Anscher, M.S.; Jirtle, R.L.; Ensminger, W.D.; Fajardo, L.F. Hepatic toxicity resulting from cancer treatment. Int. J. Radiat. Oncol. 1995, 31, 1237-1248. [CrossRef]

34. Bush, D.A.; Kayali, Z.; Grove, R.; Slater, J.D. The safety and efficacy of high-dose proton beam radiotherapy for hepatocellular carcinoma: A phase 2 prospective trial. Cancers 2011, 117, 3053-3059. [CrossRef] [PubMed]

35. Shirai, S.; Sato, M.; Noda, Y.; Kishi, K.; Kawai, N.; Minamiguchi, H.; Nakai, M.; Sanda, H.; Sahara, S.; Ikoma, A.; et al. Distribution of Functional Liver Volume in Hepatocellular Carcinoma Patients with Portal Vein Tumor Thrombus in the 1st Branch and Main Trunk Using Single Photon Emission Computed Tomography-Application to Radiation Therapy. Cancers 2011, 3, 4114-4126. [CrossRef]

36. Ohara, K.; Okumura, T.; Akisada, M.; Inada, T.; Mori, T.; Yokota, H.; Calaguas, M.J.B. Irradiation synchronized with respiration gate. Int. J. Radiat. Oncol. 1989, 17, 853-857. [CrossRef] 
37. Tsunashima, Y.; Sakae, T.; Shioyama, Y.; Kagei, K.; Terunuma, T.; Nohtomi, A.; Akine, Y. Correlation between the respiratory waveform measured using a respiratory sensor and 3D tumor motion in gated radiotherapy. Int. J. Radiat. Oncol. 2004, 60, 951-958. [CrossRef]

38. Fisher, R.A. On the Interpretation of $\chi^{2}$ from Contingency Tables, and the Calculation of P. J. R. Stat. Soc. 1922, 85, 87-94. [CrossRef]

39. Welch, B.L. The generalization of students' problem when several different population variances are involved. Biometrika 1947, 34, 28-35. [CrossRef]

40. Kanda, Y. Investigation of the freely available easy-to-use software 'EZR' for medical statistics. Bone Marrow Transplant. 2013, 48, 452-458. [CrossRef]

(C) 2020 by the authors. Licensee MDPI, Basel, Switzerland. This article is an open access article distributed under the terms and conditions of the Creative Commons Attribution (CC BY) license (http://creativecommons.org/licenses/by/4.0/). 